\title{
CÂNCER DE PRÓSTATA: ASPECTO DAS AÇÕES PREVENTIVAS REALIZADAS NA ATENÇÃO PRIMÁRIA A SAÚDE
}

\section{REVISÃO INTEGRATIVA}

SANTOS, Tereza Fernanda Pereira ${ }^{1}$

MOTA, Flávia Bianca Suíça ${ }^{2}$

SANTOS, Tereza Fernanda Pereira. MOTA, Flávia Bianca Suíça. Cancêr de próstata: Aspecto das ações preventivas realizadas na atenção primária a saúde. Revista Científica Multidisciplinar Núcleo do Conhecimento. Ano 04, Ed. 10, Vol. 01, pp. 05-24. Outubro de 2019. ISSN: 2448-0959, Link de acesso: https://www.nucleodoconhecimento.com.br/saude/acoes-preventivas

\section{RESUMO}

O Câncer de próstata é o tumor que afeta a próstata, glândula situada abaixo da bexiga e que abrange a uretra, canal que liga a bexiga ao orifício externo do pênis, tendo sua maior frequência no sexo masculino, depois do câncer de pele. Trata-se de uma revisão integrativa da literatura de caráter exploratório com abordagem qualitativa. Foram incluídos os estudos publicados no período de 2012 a 2017, depois de realizada a filtragem, utilizando-se dos critérios de exclusão e foram escolhidas 11 produções científicas que compuseram a discussão desta Revisão Integrativa. $O$ objetivo geral da pesquisa foi descrever os principais aspectos acerca das atividades realizadas no âmbito da APS, na prevenção do câncer de próstata. Foram

\footnotetext{
1 Pós-Graduada em Saúde da Família; Gestão em Saúde Pública; Enfermagem em Urgência e Emergência e Terapia Intensiva; Graduada pela Faculdade Estácio de Sergipe.

2 Mestrado em Saúde e Ambiente; Especialização em andamento em enfermagem oncológica; Especialização em Enfermagem do trabalho; Graduação em Enfermagem.
} 
estabelecidos os seguintes objetivos específicos: elencar as principais ações de prevenção ao câncer de próstata realizadas na APS no Brasil, relatar as dificuldades enfrentadas pelo enfermeiro na implementação de atividades direcionadas a prevenção e rastreamento do câncer de próstata e descrever os fatores mais relevantes para o desenvolvimento de neoplasias prostáticas. Conclui-se que o câncer de próstata continua sendo um problema de saúde pública de grandes proporções, mas que ao longo dos anos vêm se buscando ações para sua diminuição. Cabe ressaltar também que há um empenho dos profissionais da saúde para programar ações direcionadas aos usuários do sexo masculino.

Palavras-chave: Atenção Primária, neoplasias de próstata, enfermagem, saúde do homem.

\section{INTRODUÇÃO}

A próstata é um órgão que compõe o sistema reprodutor masculino, ela possui a função de excreção de parte do fluido seminal, além de proteger e nutrir os espermatozoides, estando localizada sob a bexiga e a anterior ao reto. No entanto, a falta de informação por parte da população masculina sobre o próprio corpo, assim como das doenças específicas do gênero, acarreta numa grande dificuldade destes em saber a localização da próstata e sua função no organismo (MEDEIROS et al., 2011).

Historicamente os homens não se atentam muito aos fatores referentes à sua saúde, de modo que esperam sempre o agravamento dos sintomas e o comprometimento da sua qualidade de vida, para procurar ajuda do serviço de saúde. A população masculina demonstra maior vulnerabilidade a problemas de saúde em relação as mulheres, por conta disso a incidência de mortes por doenças tratáveis ou evitáveis aumenta e acontece cada vez mais precocemente (POZZATI et al., 2014).

Somente no ano de 2013 ocorreram mais de 14 mil óbitos por câncer de próstata (CP) no Brasil, a estimativa para o ano de 2016 é de que ocorrerá algo em torno de 61.200 novos casos da doença no país. No entanto, estima-se que ainda ocorra um aumento 
de cerca de $60 \%$ no número de novos casos de $\mathrm{CP}$, devido ao aumento da expectativa de vida da população mundial (PORTO et al., 2016).

Oliveira et al. (2015) relatam que existem três principais fatores que predispõe o indivíduo ao surgimento de neoplasias prostáticas, são eles: idade, etnia e predisposição genética. Entretanto, outras evidências clínicas levam a crer na influência de componentes externos como: alimentação, sexualidade, consumo de drogas, etilismo, exposição a agentes radiológicos, exposição ao sol e problemas ocupacionais.

Considerada a porta de entrada do sistema de saúde no Brasil a Atenção Primaria à Saúde (APS), possui a responsabilidade de promover ações de saúde, no âmbito individual e coletivo, visando sempre a proteção da saúde, prevenção de agravos, estabelecimento de diagnóstico, tratamento, reabilitação, redução de danos e a manutenção da saúde, objetivando subsidiar ao usuário do Sistema Único de Saúde (SUS) uma atenção integral, influenciando positivamente na qualidade de vida da população (BRASIL, 2012).

Visando reduzir a limitação do sistema de saúde quanto à fragilidade do desenvolvimento de ações específicas voltadas a saúde do homem, o Ministério da Saúde (MS) formulou a Política Nacional de Atenção Integral à Saúde do Homem (PNAISH), objetivando melhorar a qualidade da assistência prestada à saúde masculina resguardando a integralidade das ações para que desta forma seja garantida a promoção da saúde e a prevenção de agravos evitáveis (SILVA et al., 2012).

O advento da PNAISH foi crucial no fortalecimento da atenção a saúde do homem na APS, porém, estas mudanças foram pouco impactantes no SUS, de modo que não foi possível relacionar a ausência do homem nos serviços de saúde à oferta de programas direcionados a população masculina ou ao horário de funcionamento dos serviços que muitas vezes coincidem com o trabalho dos usuários. É necessário que o homem seja incorporado as atividades programadas como protagonista, para assim 
reduzir as complicações e agravos inerentes a saúde desses usuários (OLIVEIRA et al., 2015).

O aspecto multiprofissional é essencial para que as orientações prestadas aos usuários sejam recepcionadas de maneira satisfatória. Nesse sentido o enfermeiro é peça chave na identificação dos principais fatores de risco que cercam o paciente, assim como, da detecção precoce dos sinais e sintomas referentes a possíveis patologias. Cabe a este profissional ainda, formar vínculo com estes usuários para que a assistência de enfermagem seja implementada com efetividade, demonstrando ao homem a importância do cuidado com a saúde (ALMEIDA et al., 2016).

A prevenção do surgimento de novos casos de câncer é atualmente um grande desafio enfrentado pela comunidade científica e os gestores de saúde em todo planeta. Todo o percurso dos pacientes desde a entrada no serviço de saúde é tratado com bastante relevância, haja vista que de posse dessas informações, há a possibilidade de formulação de estratégias que visam reduzir o tempo gasto desde o diagnostico até o tratamento, reduzindo significativamente a mortalidade provocada pelo longo período de espera (AQUINO, 2016).

É preciso que todos os que compõem a equipe multiprofissional de saúde se comprometam no fortalecimento das ações de saúde inclusivas voltadas a população masculina, permitindo que estes usuários possam ter acesso aos métodos de rastreamento e detecção precoce de $\mathrm{CP}$, superando preconceitos e a cultura que remete a imagem do homem a um ser que não possui problemas de saúde (SILVEIRA et al., 2017).

A hipótese que norteou o estudo foi a seguinte: As ações desenvolvidas na APS com foco na prevenção do câncer de próstata não são suficientes. Contudo, foi estabelecida seguinte questão norteadora para a presente investigação: Qual a realidade das ações preventivas relacionadas ao câncer de próstata a partir da APS no Brasil? 
Diante de crescente incidência de casos de câncer de próstata que atingem a população masculina e da escassez de atividades relacionadas a ações preventivas de CP o estudo justifica-se pela importância de disponibilizar a comunidade científica informações atualizadas e relevantes a respeito da saúde do homem e rastreamento precoce de neoplasias da próstata na Atenção Básica, descrevendo as ações preventivas relacionadas ao câncer de próstata e os principais aspectos que cercam a doença na APS.

O objetivo geral da pesquisa foi descrever os principais aspectos acerca das atividades realizadas no âmbito da APS, na prevenção do câncer de próstata. Foram estabelecidos os seguintes objetivos específicos: elencar as principais ações de prevenção ao câncer de próstata realizadas na APS no Brasil, relatar as dificuldades enfrentadas pelo enfermeiro na implementação de atividades direcionadas a prevenção e rastreamento do câncer de próstata e descrever os fatores mais relevantes para o desenvolvimento de neoplasias prostáticas.

\section{MÉTODO}

Trata-se de uma Revisão Integrativa da literatura de caráter exploratório com abordagem qualitativa. Segundo Mendes (2008) a natureza desse tipo de estudo exige formulação de uma questão norteadora para pesquisa, sendo que o pesquisador deve atentar quanto o processo exploratório rigoroso e padronizado da literatura disponível, possibilitando a discussão e análise dos achados científicos de determinada área, promovendo maior aprofundamento e conhecimento do fenômeno estudado.

O processo de obtenção das informações necessárias para a coleta dos dados da pesquisa percorreu as seguintes etapas: pesquisa dos descritores obtidos por meio do DeCS (Descritores em Ciências da Saúde). Foram estabelecidos os seguintes: Atenção Primária. Neoplasias de Próstata. Enfermagem e Saúde do Homem. Os operadores booleanos utilizados no refinamento da pesquisa nas bases eletrônica de dados foram os termos END e OR. 
A amostra dos estudos que compuseram a pesquisa foi extraída a partir de dados oriundos de artigos científicos disponíveis nas principais bases de dados eletrônicos da internet como: BVS (Biblioteca Virtual em Saúde) e SciELO (Scientific Electronic Library Online), LILACS e BDEnf (Base de Dados em Enfermagem), no período de Julho de 2016 à abril de 2017 e foi composta por artigos publicados nos últimos cinco anos, ou seja, publicados entre os períodos de 2012 a 2017.

Foram incluídos os estudos publicados no período de 2012 a 2017, estudos de origem estrangeira com sua tradução disponível, estudos completos, estudo com cuja metodologia obedeça às etapas previstas para cada tipo de pesquisa e estudos disponíveis gratuitamente nas bases dados selecionados. Foram excluídos os estudos que fugiam da temática proposta, pesquisa que abordavam aspectos alheios a APS, pesquisas com traduções parciais e artigos fragmentados.

Para a análise dos dados, o estudo contou com o método proposto por Mendes et al. (2008), composto pelas seguinte etapas: identificação do tema e seleção da hipótese e questão de pesquisa para a elaboração da revisão integrativa; estabelecimento de critérios para inclusão e exclusão de estudos; definição das informações a serem extraídas dos estudos selecionados; categorização dos estudos; avaliação dos estudos incluídos na revisão integrativa; interpretação dos resultados e apresentação da revisão/síntese do conhecimento.

$\mathrm{Na}$ etapa de análise qualitativa dos dados, foi realizada minuciosa leitura do conteúdo pesquisado em que os dados relevantes foram extraídos e tabulados em instrumentos desenvolvidos pelos autores. As informações subsidiaram a discussão dos achados, para tanto os itens que compuseram o quadro foram: título do estudo, tipo de pesquisa, resultados e conclusão. A presente pesquisa obedeceu aos critérios de ética em pesquisa fundamentados nas normas da ABNT 10520 e 6023, no qual se podem extrair as exigências necessárias para a realização de citações e referências. E na lei $12.853 / 13$ que regulamenta os direitos autorais. 


\section{RESULTADOS}

Após a utilização dos descritores pré-estabelecidos para esta pesquisa, obteve-se como primeiro resultado com 435 publicações. Em seguida foi realizada a filtragem, utilizando-se dos critérios de exclusão, restando 98 estudos, que tiveram seus resumos avaliados. No final foram escolhidas 11 produções científicas que compuseram a discussão desta Revisão Integrativa como demonstra o gráfico 1.

Gráfico 1: Distribuição dos estudos de acordo com suas respectivas bases de dados.

\section{Distribução da Amostra}

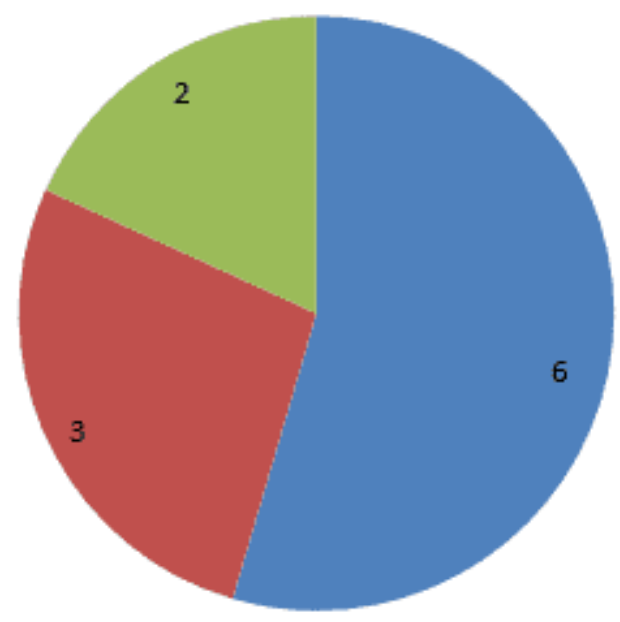

Bdenf

- Scielo

- LILACS

Fonte: Autoras, 2017.

Os resultados obtidos foram tabulados de acordo com o ano de publicação, autores, tipo de pesquisa e conclusão como demonstra o quadro 1. Diante dos resultados obtidos foram estabelecidos 4 eixos temáticos, para melhor explanar sobre os assuntos relativos ao câncer de próstata e as ações protetivas realizadas, sendo eles: Aspectos epidemiológicos do câncer de próstata, principais fatores para o desenvolvimento de câncer da próstata, dificuldades enfrentadas pelo enfermeiro frente às ações de prevenção do câncer de próstata na APS e ações preventivas do câncer de próstata na atenção primária. 
Quadro 1: Resultados da sumarização dos artigos de acordo com o ano de publicação, autores, tipo de pesquisa e conclusão.

\begin{tabular}{|c|c|c|c|}
\hline $\begin{array}{lr}\text { AUTOR } & E \\
\text { ANO } & \text { DE } \\
\text { PUBLICAÇÃO }\end{array}$ & TÍTULOS & $\begin{array}{ll}\text { TIPO } & \text { DE } \\
\text { PESQUISA } & \end{array}$ & RESULTADOS \\
\hline $\begin{array}{l}\text { CAMPOS et } \\
\text { al., } 2011\end{array}$ & $\begin{array}{l}\text { Aspectos culturais } \\
\text { que envolvem o } \\
\text { paciente com } \\
\text { diagnóstico de } \\
\text { neoplasia de } \\
\text { próstata: um estudo } \\
\text { na comunidade. }\end{array}$ & $\begin{array}{l}\text { Realizou-se uma } \\
\text { pesquisa } \\
\text { quantitativa, } \\
\text { exploratória, } \\
\text { empregando a } \\
\text { técnica } \\
\text { questionário } \\
\text { estruturado. }\end{array}$ & $\begin{array}{l}\text { Os aspectos culturais e } \\
\text { sociais, como: } \\
\text { masculinidade, } \\
\text { educação, família, } \\
\text { crenças e mitos, que } \\
\text { envolvem o câncer de } \\
\text { próstata, influenciam } \\
\text { diretamente em como } \\
\text { os pacientes convivem } \\
\text { com o diagnóstico do } \\
\text { câncer de próstata. }\end{array}$ \\
\hline $\begin{array}{l}\text { ALVES et al., } \\
2011\end{array}$ & $\begin{array}{l}\text { Gênero e saúde: o } \\
\text { cuidar do homem } \\
\text { em debate. }\end{array}$ & $\begin{array}{l}\text { O estudo foi de } \\
\text { caráter } \\
\text { transversal, } \\
\text { descritivo } \\
\text { analítico, com } \\
\text { abordagem } \\
\text { quantitativa } \\
\text { qualitativa. }\end{array}$ & $\begin{array}{l}\text { A prevenção ao câncer } \\
\text { de próstata foi o } \\
\text { aspecto mais apontado } \\
\text { quando a preocupação } \\
\text { é a saúde. }\end{array}$ \\
\hline $\begin{array}{l}\text { PAIVA et al., } \\
2011 .\end{array}$ & $\begin{array}{l}\text { Barreiras em } \\
\text { relação aos exames } \\
\text { de rastreamento do } \\
\text { câncer de próstata. }\end{array}$ & $\begin{array}{l}\text { Realizou-se } \\
\text { estudo seccional, } \\
\text { desenvolvido por } \\
\text { meio de inquérito } \\
\text { domiciliar. }\end{array}$ & $\begin{array}{l}\text { Embora não seja o } \\
\text { único determinante, } \\
\text { disseminar } \\
\text { conhecimentos } \\
\text { adequados sobre o } \\
\text { exame pode se } \\
\text { constituir em estratégia }\end{array}$ \\
\hline
\end{tabular}




\begin{tabular}{|c|c|c|c|}
\hline & & & $\begin{array}{l}\text { fundamental para a } \\
\text { formação de } \\
\text { atitude positiva em } \\
\text { relação à detecção } \\
\text { precoce. }\end{array}$ \\
\hline $\begin{array}{l}\text { OLIVEIRA; } \\
\text { POPOV, } 2012 .\end{array}$ & $\begin{array}{l}\text { Exame preventivo } \\
\text { do câncer de } \\
\text { próstata: } \\
\text { impressões } \\
\text { sentimentos. }\end{array}$ & $\begin{array}{l}\text { Pesquisa } \\
\text { qualitativa, a qual } \\
\text { teve como } \\
\text { princípios } \\
\text { metodológicos a } \\
\text { análise do } \\
\text { discurso do sujeito } \\
\text { e como referencial } \\
\text { teórico a } \\
\text { fenomenologia. }\end{array}$ & $\begin{array}{l}\text { A ciência dos } \\
\text { principais sentimentos } \\
\text { envolvidos antes, } \\
\text { durante e após os } \\
\text { exames preventivos de } \\
\text { câncer de próstata, } \\
\text { podem subsidiar o } \\
\text { enfermeiro na } \\
\text { promoção de } \\
\text { estratégias para } \\
\text { melhor compreender } \\
\text { os fatores } \\
\text { comportamentais e } \\
\text { psicossociais } \\
\text { masculinos. }\end{array}$ \\
\hline $\begin{array}{l}\text { DUARTE; } \\
\text { OLIVEIRA; } \\
\text { SOUZA, } 2012 .\end{array}$ & $\begin{array}{l}\text { A Política Saúde do } \\
\text { Homem e sua } \\
\text { operacionalização } \\
\text { na Atenção Primária } \\
\text { à Saúde. }\end{array}$ & $\begin{array}{l}\text { O estudo foi de } \\
\text { caráter } \\
\text { transversal, } \\
\text { descritivo r e } \\
\text { analítico, com } \\
\text { abordagem } \\
\text { quantitativa } \\
\text { qualitativa. }\end{array}$ & $\begin{array}{l}\text { Aponta-se da } \\
\text { envolvimento dasculina } \\
\text { população manejamento da } \\
\text { no planejam à ara } \\
\text { oferta da atenço á } \\
\text { saúde como meio para } \\
\text { adesão do homem às } \\
\text { ações de Promoção da } \\
\text { Saúde. }\end{array}$ \\
\hline $\begin{array}{l}\text { LIMA et al., } \\
2013 .\end{array}$ & $\begin{array}{l}\text { Avaliação } \\
\text { Nutricional }\end{array}$ & $\begin{array}{ll}\mathrm{O} & \text { trabalho } \\
\text { constou } & \text { de um }\end{array}$ & $\begin{array}{l}\text { Percebe-se que o } \\
\text { tempo de convívio com }\end{array}$ \\
\hline
\end{tabular}




\begin{tabular}{|l|l|l|l|}
\hline Pacientes & delineamento & a neoplasia e o grau de \\
Oncológicos Adultos & transversal com são & severidade, de \\
e Idosos Internados & uma amostra de & fatores determinantes \\
e Ambulatoriais de & 39 indivíduos & para o resultado da \\
um Hospital Geral. & $\begin{array}{l}\text { adultos e idosos } \\
\text { internados } \\
\text { ambulatoriais. }\end{array}$ & avaliação nutricional. \\
\hline
\end{tabular}

\begin{tabular}{|c|c|c|c|}
\hline $\begin{array}{l}\text { AUTOR E ANO } \\
\text { DE } \\
\text { PUBLICAÇÃO }\end{array}$ & TÍTULOS & $\begin{array}{ll}\text { TIPO } & \text { DE } \\
\text { PESQUISA } & \end{array}$ & RESULTADOS \\
\hline $\begin{array}{l}\text { VIEIRA et al., } \\
2013 .\end{array}$ & $\begin{array}{l}\text { Atendimento da } \\
\text { população } \\
\text { masculina em } \\
\text { unidade básica } \\
\text { saúde da família: } \\
\text { motivos para a } \\
\text { (não) procura }\end{array}$ & $\begin{array}{l}\text { Realizou-se um } \\
\text { estudo descritivo, } \\
\text { com abordagem } \\
\text { quantitativa, por } \\
\text { meio de pesquisa } \\
\text { documental. }\end{array}$ & $\begin{array}{l}\text { Para atender às } \\
\text { peculiaridades da } \\
\text { população masculina, } \\
\text { é necessário que os } \\
\text { profissionais de saúde } \\
\text { se capacitem, } \\
\text { problematizem a } \\
\text { realidade de cada } \\
\text { UBSF e juntamente } \\
\text { com os gestores, } \\
\text { vislumbrem } \\
\text { operacionalizem } \\
\text { estratégias inclusivas } \\
\text { de atendimento. }\end{array}$ \\
\hline $\begin{array}{l}\text { SANTIAGO et } \\
\text { al., } 2013 .\end{array}$ & $\begin{array}{lr}\text { Prevalência } & \text { e } \\
\text { fatores associados } \\
\text { à realização de } \\
\text { exames de } \\
\text { rastreamento para }\end{array}$ & $\begin{array}{l}\text { Estudo transversal, } \\
\text { desenvolvido com } \\
\text { dados do projeto } \\
\text { de pesquisa } \\
\text { "Envelhecimento }\end{array}$ & $\begin{array}{l}\text { O estudo evidencia } \\
\text { que muitos idosos têm } \\
\text { aderido à prática do } \\
\text { rastreamento e a } \\
\text { necessidade }\end{array}$ \\
\hline
\end{tabular}




\begin{tabular}{|c|c|c|c|}
\hline & $\begin{array}{l}\text { câncer de próstata } \\
\text { em idosos de Juiz } \\
\text { de Fora, MG, } \\
\text { Brasil }\end{array}$ & $\begin{array}{l}\text { populacional } \\
\text { câncer. }\end{array}$ & $\begin{array}{lr}\text { dimensionar } & \text { e } \\
\text { qualificar esse } \\
\text { processo, tendo em } \\
\text { vista suas possíveis } \\
\text { repercussões na } \\
\text { saúde pública. }\end{array}$ \\
\hline $\begin{array}{l}\text { SILVA; } \\
\text { MACHADO, } \\
2013 .\end{array}$ & $\begin{array}{l}\text { Acolhimento às } \\
\text { percepções dos } \\
\text { usuários do } \\
\text { sistema único de } \\
\text { saúde. }\end{array}$ & $\begin{array}{l}\text { Estudo descritivo- } \\
\text { exploratório com } \\
\text { abordagem } \\
\text { qualitativa. Coleta } \\
\text { de dados mediante } \\
\text { entrevista gravada }\end{array}$ & $\begin{array}{l}\text { O tempo de espera } \\
\text { prolongado e a falta de } \\
\text { profissionais e de } \\
\text { informações } \\
\text { adequadas, não } \\
\text { havendo profissionais } \\
\text { em número suficiente } \\
\text { para a demanda da } \\
\text { população. }\end{array}$ \\
\hline $\begin{array}{l}\text { NOGUEIRA; } \\
\text { NEVES, } 2013\end{array}$ & $\begin{array}{l}\text { Prevenção do } \\
\text { câncer de } \\
\text { próstata: atuação } \\
\text { dos enfermeiros } \\
\text { nas unidades de } \\
\text { atenção primária a } \\
\text { saúde. }\end{array}$ & $\begin{array}{l}\text { Trata-se de uma } \\
\text { pesquisa com } \\
\text { abordagem } \\
\text { qualitativa do tipo } \\
\text { exploratória. }\end{array}$ & $\begin{array}{l}\text { A educação em saúde } \\
\text { em conjunto com } \\
\text { outras medidas } \\
\text { importantes para a } \\
\text { saúde da população } \\
\text { masculina pode ajudar } \\
\text { a diminuir a incidência } \\
\text { do câncer de próstata. }\end{array}$ \\
\hline $\begin{array}{l}\text { SEPARAVICH; } \\
\text { CANESQUI, } \\
2013\end{array}$ & $\begin{array}{l}\text { Saúde do homem } \\
\text { e masculinidades } \\
\text { na Política } \\
\text { Nacional de } \\
\text { Atenção Integral à } \\
\text { Saúde do Homem: } \\
\text { uma revisão } \\
\text { bibliográfica. }\end{array}$ & $\begin{array}{l}\text { Para pesquisar os } \\
\text { textos sobre saúde } \\
\text { do homem e } \\
\text { masculinidades, foi } \\
\text { utilizada a } \\
\text { Biblioteca Virtual } \\
\text { em Saúde (BVS). }\end{array}$ & $\begin{array}{lr}\text { As diferentes } \\
\text { masculinidades } \\
\text { encontram-se } \\
\text { imbricadas } \\
\text { processo } \\
\text { saúde/doença vivido } \\
\text { pelos homens. Elas } \\
\text { devem }\end{array}$ \\
\hline
\end{tabular}


de saúde.

Fonte: Autoras, 2016.

\section{DISCUSSÃO}

\section{ASPECTOS EPIDEMIOLÓGICOS DO CÂNCER DE PRÓSTATA}

No Brasil, o CP é o segundo tipo de câncer com maior prevalência entre os homens, ficando atrás apenas do câncer de pele não melanoma. De acordo com o Ministério da Saúde, no ano e 2009 o total de mortes por CP foi de 12. 274 casos, destacandose o estado de São Paulo com o maior índice de mortalidade (2.697). Estima-se que em todo o planeta este seja o sexto tipo de câncer mais comum, acometendo cerca de dez por cento de todos os canceres (OLIVEIRA; POPOV, 2012).

De acordo com Campos et al. (2011) o câncer é uma doença crônica degenerativa, de longa duração, tendo como principal causa o crescimento desordenado das células. O CP em geral cresce de maneira lenta, demorando de dois a quatro anos para que este duplique. Esta neoplasia para atingir $1 \mathrm{~cm}$ chega a demorar 15 anos, sendo que com o passar do tempo há uma aceleração deste crescimento. Devido à lenta progressão e ausência de sinais e sintomas precoces, uma quantidade elevada de portadores de CP morre sem que sejam diagnosticados.

O CP é considerado uma doença típica da terceira idade, sendo muito difícil encontrar casos ocorridos antes dos 50 anos. A transição demográfica e o respectivo aumento da longevidade trouxeram junto à evolução de métodos diagnósticos como a dosagem dos níveis sanguíneos do Antígeno Prostático Específico (PSA), toque retal e ultrassonografia transretal, aumentando o número de diagnósticos em todo o mundo (SANTIAGO, et al., 2013). 
O PSA é uma proteína originada na próstata e eliminada no sêmen, o aumento nos níveis desta proteína sugere alguma alteração deste órgão podendo ter relação com algumas inflamações (prostatite), hiperplasia prostática benigna (HPB) e câncer de próstata. Apesar de ser uma ferramenta de simples detecção a sua acurácia quanto a especificidade não substitui a realização do toque retal, que possibilita o profissional avaliar as dimensões e a presença de nodulações (OLIVEIRA, et al., 2016).

\section{PRINCIPAIS FATORES PARA O DESENVOLVIMENTO DE CÂNCER DA PRÓSTATA}

Pinheiro, Cabral e Barbosa (2015) destacam os principais fatores de risco para o desenvolvimento de neoplasias prostáticas entre eles encontram-se: idade, hereditariedade, origem étnica e alimentação. No entanto, a modificação de alguns hábitos alimentares influência de maneira positiva na diminuição da possibilidade de desenvolvimento da doença. O tabagismo ocupa destaque, pois eleva em até $61 \%$ a chance de desenvolvimento de câncer e até morte em pacientes já portadores.

São desconhecidos os fatores que atuam de maneira direta na origem das neoplasias, restando apenas evidências de que dieta rica em hortaliças, fibras, cereais, frutas, e pouca gordura, promovem ações protetoras contra o surgimento de tumores. Além disso, também foram colocados como fatores de risco o crescimento paralelo à insulina, vasectomia, etilismo e fumo (LIMA, 2013).

De acordo com o envelhecimento do homem a próstata tende a aumentar o seu tamanho, fato que evolui de maneira assintomática, o fato é que este aumento pode estar relacionado a presença de tumores. Os principais sinais e sintomas são dificuldade ao urinar, presença de sangue na urina ou no esperma. Alguns pacientes relatam dor óssea, edemas em membro e genital, anemia e perda de peso. Em casos com metástase o tratamento recomentado é endócrino, enquanto os com tumores localizados a indicação é remoção da próstata ou radioterapia (VIEIRA, 2013). 


\section{DIFICULDADES ENFRENTADAS PELO ENFERMEIRO FRENTE ÀS AÇÕES DE PREVENÇÃO DO CÂNCER DE PRÓSTATA NA APS}

Em toda a trajetória do SUS foi perceptível a ausência de políticas e programas de saúde que tivesse como protagonista o homem, uma deficiência que fora evidenciada diante da elevada taxa de morte desta população. Diante disso, visando a promoção de melhorias na saúde do público masculino o Ministério da Saúde instituiu o PNAISH, que possui o intuito de orientar os programas de saúde voltados aos homens, com vistas sempre na integralidade e equidade, e humanização (EID; KOHN; MOTTA, 2014).

De acordo com Alves et al. (2011) a PNAISH procura identificar os principais fatores desencadeantes de processos patológicos no homem, assim como, aqueles que dificultam o acesso deste na APS. O Programa sugere uma modificação de aspecto cultural a respeito do processo de prevenção de agravos, evidenciando a necessidade da mudança de hábitos em relação ao cuidado com a saúde, sempre dentro do contexto que se encontra o universo masculino.

Para Silva e Machado (2013) os enfermeiros no Brasil enfrentam grande dificuldade para absorver a demanda apresentada pelos homens, por falta de incentivo organizacional ou pelo fato das campanhas de saúde não serem direcionadas ao público masculino. A partir desta situação percebeu-se que há a necessidade de alterar a maneira de aproximação deste público, visto que é algo relativamente novo e que precisa de aperfeiçoamento.

Rodrigues et al. (2016) relata que outra dificuldade enfrentada por parte dos enfermeiros está relacionada ao desinteresse dos homens em procurar os estabelecimentos de saúde. É importante frisar que os problemas assistenciais como falta de melhorias relativas ao primeiro acesso, longo período de espera para a realização da consulta e dificuldade na realização de exames vão de encontro às características masculinas de praticidade e superficialidade no enfrentamento da doença. 
A procura do serviço de saúde por parte dos homens geralmente é feita apenas em situações de urgência ou quando a situação não pode ser resolvida no primeiro nível de atenção à saúde, dificultando o estabelecimento de vínculo desses usuários. É notória a falta de informação, a rotina defasada dos serviços de saúde que abrangem o homem, o preconceito quanto a realização de exames preventivos para detecção precoce do CP e idade ideal para realização (NOGUEIRA; NEVES, 2013).

\section{AÇÕES PREVENTIVAS DO CÂNCER DE PRÓSTATA NA ATENÇÃO PRIMÁRIA}

As medidas preventivas é o método mais eficaz para o tratamento e também o mais barato, pois os casos diagnosticados tardiamente costumam custar muito caro e acabam tendo desfecho trágico. O exame anual do toque da próstata aliado ao PSA é o método disponível mais eficaz no combate à doença. A sociedade brasileira de urologia preconiza que todos os homes a partir dos 50 anos realizem, e os que possuem histórico na família iniciem já a partir dos 40 anos (SEPARAVICH; CANESQUI, 2013).

Diante do problema que é o CP, o Ministério da Saúde estabeleceu a Política Nacional de Prevenção e Controle do Câncer da Próstata, com o objetivo de reduzir a incidência, assim como a quantidade de óbitos ocasionados pela doença. O programa propõe que sejam desenvolvidas ações constantes que sinalizam a população quanto a importância do rastreamento e tratamento integral dos casos (PAIVA, et al., 2011).

Os usuários do sexo masculinos possuem algumas peculiaridades que devem ser levadas em consideração sempre quando forem desenvolvidas ações voltadas a este público. A equipe multiprofissional deve privilegiar dinâmicas em pequenos grupos de reflexão, onde estes possam tanto falar como ser ouvidos. Desta forma fica mais fácil discutir assuntos referentes ao universo masculino, permitindo aos participantes compartilhar opiniões, sugestões e experiências (DUARTE; OLIVEIRA; SOUZA, 2012). 
Os profissionais da enfermagem devem estar atentos a todas as oportunidades de realização de ações voltadas ao público masculino, haja vista que os serviços de saúde precisam aprimorar este contato a fim de solucionar ou minimizar os agravos decorrentes da falta de estímulo, priorizando sempre atividades que busquem elucidar dúvidas, e identificar de maneira precoce o surgimento de fatores predisponentes ao CP (NOGUEIRA; NEVES, 2013).

\section{CONSIDERAÇÕES FINAIS}

Os fatores de risco apontados nesta pesquisa como alerta para rastreio na comunidade foram os seguintes: idade, hereditariedade, origem étnica, alimentação e tabagismo como aspectos que exercem grandes influências no desenvolvimento do Câncer de próstata.

O estudo evidencia que o câncer de próstata continua sendo um problema de saúde pública de grandes proporções, haja vista que é o segundo tipo de câncer com maior prevalência entre a população masculina, que devido ausência de sinais e sintomas precoces acabam sendo diagnosticados tardiamente. Alguns autores em seus estudos evidenciaram que os homens na maioria das vezes procuram os serviços de saúde quando sentem algum desconforto.

Cabe ressaltar que há um empenho dos profissionais para programar ações direcionadas aos usuários do sexo masculino, porém encontram uma grande barreira relacionada à desmistificação da masculinidade. O preconceito é outro fator a ser vencido, pois para que os homens procurem os serviços antes do problema instalado, é necessária a adoção de medidas preventivas com foco no perfil masculino.

Ficou claro que o advento da PNASH e da Política Nacional de Prevenção e Controle do Câncer da Próstata facilitaram muito a aproximação da Unidade Básica de Saúde aos usuários do sexo masculino. Sempre foi um enorme desafio enfrentado pelos profissionais atuantes na APS, uma vez que no decorrer da história a pesquisa demonstra que o público masculino não tinha atividades que priorizassem a melhor maneira de abordagem e aproximação desses ao serviço público de saúde. 
Foi possível compreender que a Política Nacional de Prevenção e Controle do Câncer de Próstata tem como intenção diminuir os casos da doença, além disso, os programas desenvolvidos propõem que ações sejam desenvolvidas para que possam de forma constante sinalizar toda a população quanto a relevância de rastrear os casos.

Conclui-se, que é necessária a formulação de novas pesquisas acerca das ações que devem ser realizadas na APS, para que o princípio da equidade proposto pelo modelo de saúde pública vigente no Brasil possibilite a equipe de saúde o estabelecimento de uma relação eficaz entre usuário e profissionais, possibilitando desta forma o trabalho em conjunto, para que assim sejam vencidas as dificuldades, aumentando a adesão dos homens nas ações preventivas, de acordo com a peculiaridade de cada cliente.

Contudo, nunca foi propósito do presente estudo esgotar toda a temática que envolve às ações preventivas realizadas na APS para prevenção do câncer de próstata. No entanto, o assunto aqui abordado serve como fonte de informações atualizadas a comunidade científica em geral, fomentando a formulação de novos estudos, possibilitando a elaboração de estratégias de atenção à saúde do homem mais precisas, com foco nas características e necessidades deste público.

\section{REFERÊNCIAS}

ALMEIDA, G.C.M. et al. Atuação do profissional de enfermagem do trabalho na prevenção do câncer de próstata. Enfermagem Brasil, v. 15, n. 1, 2016.

ALVES, R. F. et al., Gênero e saúde: o cuidar do homem em debate. Psicologia: teoria e prática, v. 13, n. 3, p. 152-166, 2011.

AQUINO, R. C. A.; RODRIGUES, M. Acesso e itinerário terapêutico dos pacientes com câncer: principais dificuldades enfrentadas para este percurso. Saúde.com, v. 12, n. 1, 2016. 
CAMPOS, H.L.M. et al., Aspectos culturais que envolvem o paciente com diagnóstico de neoplasia de próstata: um estudo na comunidade. Rev. bras. cancerol. v. 57, n. 4, p. 493-501, 2011.

DUARTE, S. J. H.; OLIVEIRA, J. R.; SOUZA, R.R. A Política Saúde do Homem e sua operacionalização na Atenção Primária à Saúde. Gestão e Saúde, v. 3, n. 1, p. pag. 520-530, 2012.

EID, A.P.; KOHN, K.C.; MOTTA, R.F. Política de saúde do homem: para além do que se vê. Diaphora, v. 12, n. 2, p. 70-78, 2014.

LIMA, D.M. et al. Avaliação Nutricional de Pacientes Oncológicos Adultos e Idosos Internados e Ambulatoriais de um Hospital Geral. Revista Contexto \& Saúde, v. 3, n. 05, p. 17-36, 2013.

MEDEIROS, A. P. et al. Fatores de risco e medidas de prevenção do câncer de próstata: subsídios para a enfermagem. Rev. bras. enferm, v. 64, n. 2, p. 385-388, 2011.

MENDES, K.D.S. et al. Revisão integrativa: método de pesquisa para a incorporação de evidências na saúde e na enfermagem. Texto \& Contexto-Enfermagem, v. 17, n. 4, p. 758-764, 2008.

NOGUEIRA, H.L.; NEVES, J. B. Prevenção do câncer de próstata: atuação dos enfermeiros nas unidades de atenção primária a saúde. Revista Enfermagem Integrada, v. 6, n. 1, p. 1098-1109, 2013.

OLIVEIRA, A.J.R. et al. A atuação da enfermagem frente às barreiras encontradas no diagnóstico precoce do câncer de próstata. Fasem Ciências, v. 7, n. 1, p. 29-65, 2016.

OLIVEIRA, B.N. et al. Saúde do homem na atenção primária à saúde: reflexões acerca da multiplicidade de olhares na avaliação corporal. Revista Baiana de Saúde Pública, v. 38, n. 3, p. 751-759, 2015. 
OLIVEIRA, J. I. M.; POPOV, D. C. S. Exame preventivo do câncer de próstata: impressões e sentimentos. Rev Enferm UNISA, v. 13, n. 1, p. 13-20, 2012.

PAIVA, E. P.et al., Barreiras em relação aos exames de rastreamento do câncer de próstata. Revista Latino-Americana de Enfermagem, v. 19, n. 1, p. 73-80, 2011.

PINHEIRO, J.T. G.; CABRAL, M. C. A.; BARBOSA, H. A. Perfil dos homens participantes do ensaio comunitário sobre prevenção do câncer de próstata. Revista Bionorte, v. 4, n. 1, 2015.

PORTO, S.M. et al. Vivências de homens frente ao diagnóstico de câncer de próstata. Ciência \& Saúde, v. 9, n. 2, p. 83-89, 2016.

POZZATI, R. et al. O cuidado na saúde dos homens: realidade e perspectivas. Revista Enfermagem UERJ, v. 21, n. 4, p. 540-545, 2014.

RODRIGUES, T. C. et al. Percepção das equipes de saúde da família sobre a implantação da política saúde do homem. Gestão e Saúde, n. supl., p. 906-925, 2016.

SANTIAGO, L. M. et al. Prevalência e fatores associados à realização de exames de rastreamento para câncer de próstata em idosos de Juiz de Fora, MG, Brasil. Ciênc. saúde coletiva, v. 18, n. 12, p. 3535-42, 2013.

SEPARAVICH, M. A.; CANESQUI, A. M. Saúde do homem e masculinidades na Política Nacional de Atenção Integral à Saúde do Homem: uma revisão bibliográfica. Saúde e Sociedade, v. 22, n. 2, p. 415-428, 2013.

SILVA, E.C.; MACHADO, P.R.F. Acolhimento as percepções dos usuários do sistema único de saúde. Revista saúde, corpo, ambiente e cuidado, v. 1, n. 1, 2013.

SILVA, P.A.S. et al. A saúde do homem na visão dos enfermeiros de uma unidade básica de saúde. Esc. Anna Nery, v. 16, n. 3, p. 561-8, 2012. 
SILVEIRA, C.L.G. et al. Atenção à saúde do homem na atenção primária em saúde: revisão integrativa. Revista de enfermagem UFPE on line-ISSN: 1981-8963, v. 11, n. 3, p. 1528-1535, 2017.

VIEIRA, K. L. D. et al. Atendimento da população masculina em unidade básica saúde da família: motivos para a (não) procura. Esc. Anna Nery, v. 17, n. 1, p. 120-7, 2013.

\section{APÊNDICE}

QUADRO 1 - Síntese das informações coletadas nos artigos.

\begin{tabular}{|c|c|c|c|}
\hline $\begin{array}{l}\text { AUTOR } \\
\text { ANO } \quad \text { DE } \\
\text { PUBLICAÇÃO }\end{array}$ & TITULOS & $\begin{array}{ll}\text { TIPO } & \text { DE } \\
\text { PESQUISA } & \end{array}$ & RESULTADOS \\
\hline $\begin{array}{l}\text { CAMPOS et } \\
\text { al., } 2011\end{array}$ & $\begin{array}{l}\text { Aspectos culturais } \\
\text { que envolvem o } \\
\text { paciente de } \\
\text { diagnóstico de } \\
\text { neoplasia do } \\
\text { próstata: um estudo } \\
\text { na comunidade. }\end{array}$ & $\begin{array}{l}\text { Realizou-se uma } \\
\text { pesquisa } \\
\text { quantitativa, } \\
\text { exploratória, } \\
\text { empregando a } \\
\text { técnica } \\
\text { questionário } \\
\text { estruturado. }\end{array}$ & $\begin{array}{l}\text { Os aspectos culturais e } \\
\text { sociais, como: } \\
\text { masculinidade, } \\
\text { educação, família, } \\
\text { crenças e mitos, que } \\
\text { envolvem o câncer de } \\
\text { próstata, influenciam } \\
\text { diretamente em como } \\
\text { os pacientes convivem } \\
\text { com o diagnóstico do } \\
\text { câncer de próstata. }\end{array}$ \\
\hline $\begin{array}{l}\text { ALVES et al., } \\
2011\end{array}$ & $\begin{array}{l}\text { Gênero e saúde: o } \\
\text { cuidar do homem } \\
\text { em debate. }\end{array}$ & $\begin{array}{l}\text { O estudo foi de } \\
\text { caráter } \\
\text { transversal, } \\
\text { descritivo } \\
\text { analítico, e com } \\
\text { abordagem }\end{array}$ & $\begin{array}{l}\text { A prevenção ao câncer } \\
\text { de próstata foi o } \\
\text { aspecto mais apontado } \\
\text { quando a preocupação } \\
\text { é a saúde. }\end{array}$ \\
\hline
\end{tabular}




\begin{tabular}{|c|c|c|c|}
\hline & & $\begin{array}{l}\text { quantitativa e } \\
\text { qualitativa. }\end{array}$ & \\
\hline $\begin{array}{l}\text { PAIVA et al., } \\
2011 .\end{array}$ & $\begin{array}{l}\text { Barreiras em } \\
\text { relação aos exames } \\
\text { de rastreamento do } \\
\text { câncer de próstata. }\end{array}$ & $\begin{array}{l}\text { Realizou-se } \\
\text { estudo seccional, } \\
\text { desenvolvido por } \\
\text { meio de inquérito } \\
\text { domiciliar. }\end{array}$ & $\begin{array}{l}\text { Embora não seja o } \\
\text { único determinante, } \\
\text { disseminar } \\
\text { conhecimentos } \\
\text { adequados sobre o } \\
\text { exame pode se } \\
\text { constituir em estratégia } \\
\text { fundamental para a } \\
\text { formação de } \\
\text { atitude positiva em } \\
\text { relação à detecção } \\
\text { precoce. }\end{array}$ \\
\hline $\begin{array}{l}\text { OLIVEIRA; } \\
\text { POPOV, } 2012 .\end{array}$ & $\begin{array}{l}\text { Exame preventivo } \\
\text { do câncer de } \\
\text { próstata: } \\
\text { impressões } \\
\text { sentimentos. }\end{array}$ & $\begin{array}{l}\text { Pesquisa } \\
\text { qualitativa, a qual } \\
\text { teve como } \\
\text { princípios } \\
\text { metodológicos a } \\
\text { análise do } \\
\text { discurso do sujeito } \\
\text { e como referencial } \\
\text { teórico a } \\
\text { fenomenologia. }\end{array}$ & $\begin{array}{l}\text { A ciência dos } \\
\text { principais sentimentos } \\
\text { envolvidos antes, } \\
\text { durante e após os } \\
\text { exames preventivos de } \\
\text { câncer de próstata, } \\
\text { podem subsidiar o } \\
\text { enfermeiro de } \\
\text { promoção para } \\
\text { estratégias compreender } \\
\text { melhor catores } \\
\text { os } \\
\text { comportamentais } \\
\text { psicossociais } \\
\text { masculinos. }\end{array}$ \\
\hline
\end{tabular}




\begin{tabular}{|c|c|c|c|}
\hline $\begin{array}{l}\text { DUARTE; } \\
\text { OLIVEIRA; } \\
\text { SOUZA, } 2012 .\end{array}$ & $\begin{array}{l}\text { A Política Saúde do } \\
\text { Homem e sua } \\
\text { operacionalização } \\
\text { na Atenção Primária } \\
\text { à Saúde. }\end{array}$ & $\begin{array}{lr}\text { O estudo foi de } \\
\text { caráter } \\
\text { transversal, } \\
\text { descritivo r e } \\
\text { analítico, com } \\
\text { abordagem } \\
\text { quantitativa } \\
\text { qualitativa. }\end{array}$ & $\begin{array}{l}\text { Aponta-se da } \\
\text { envolvimento dasculina } \\
\text { população mas da } \\
\text { no planejamento da } \\
\text { oferta da atenção à } \\
\text { saúde como meio para } \\
\text { adesão do homem às } \\
\text { ações de Promoção da } \\
\text { Saúde. }\end{array}$ \\
\hline $\begin{array}{l}\text { LIMA et al., } \\
2013 \text {. }\end{array}$ & $\begin{array}{l}\text { Avaliação } \\
\text { Nutricional de } \\
\text { Pacientes } \\
\text { Oncológicos Adultos } \\
\text { e Idosos Internados } \\
\text { e Ambulatoriais de } \\
\text { um Hospital Geral. }\end{array}$ & $\begin{array}{l}\text { O trabalho } \\
\text { constou de um } \\
\text { delineamento } \\
\text { transversal com } \\
\text { uma amostra de } \\
39 \text { indivíduos } \\
\text { adultos e idosos } \\
\text { internados e } \\
\text { ambulatoriais. }\end{array}$ & $\begin{array}{l}\text { Percebe-se que o } \\
\text { tempo de convívio com } \\
\text { a neoplasia e o grau de } \\
\text { severidade, são } \\
\text { fatores determinantes } \\
\text { para o resultado da } \\
\text { avaliação nutricional. }\end{array}$ \\
\hline $\begin{array}{l}\text { AUTOR E ANO } \\
\text { DE } \\
\text { PUBLICAÇÃO }\end{array}$ & OS & $\begin{array}{ll}\text { TIPO } & \text { DE } \\
\text { PESQUISA } & \end{array}$ & KESUL I AUUS \\
\hline $\begin{array}{l}\text { VIEIRA et al., } \\
2013 .\end{array}$ & $\begin{array}{l}\text { Atendimento da } \\
\text { população } \\
\text { masculina em } \\
\text { unidade básica } \\
\text { saúde da família: } \\
\text { motivos para a } \\
\text { (não) procura }\end{array}$ & $\begin{array}{l}\text { Realizou-se um } \\
\text { estudo descritivo, } \\
\text { com abordagem } \\
\text { quantitativa, por } \\
\text { meio de pesquisa } \\
\text { documental. }\end{array}$ & $\begin{array}{l}\text { Para atender às } \\
\text { peculiaridades da } \\
\text { população masculina, } \\
\text { é necessário que os } \\
\text { profissionais de saúde } \\
\text { se capacitem, } \\
\text { problematizem a } \\
\text { realidade de cada } \\
\text { UBSF e juntamente } \\
\text { com os gestores, }\end{array}$ \\
\hline
\end{tabular}




\begin{tabular}{|c|c|c|c|}
\hline & & & $\begin{array}{l}\text { vislumbrem } \\
\text { operacionalizem } \\
\text { estratégias inclusivas } \\
\text { de atendimento. }\end{array}$ \\
\hline $\begin{array}{l}\text { SANTIAGO et } \\
\text { al., } 2013 .\end{array}$ & 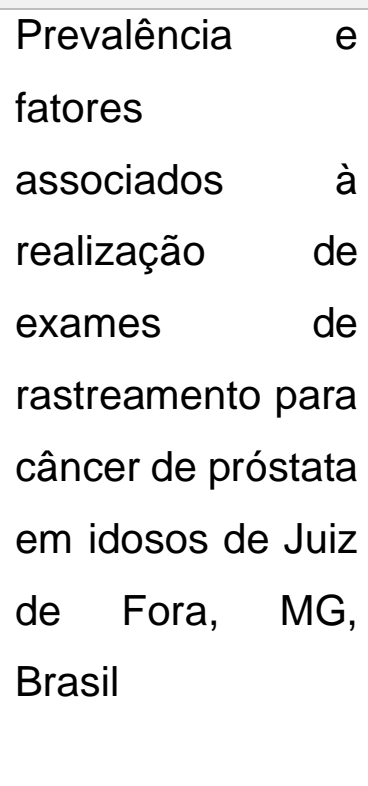 & $\begin{array}{l}\text { Estudo transversal, } \\
\text { desenvolvido com } \\
\text { dados do projeto } \\
\text { de pesquisa } \\
\text { "Envelhecimento } \\
\text { populacional e } \\
\text { câncer. }\end{array}$ & $\begin{array}{l}\text { O estudo evidencia } \\
\text { que muitos idosos têm } \\
\text { aderido à prática do } \\
\text { rastreamento e a } \\
\text { necessidade } \\
\text { dimensionar } \\
\text { qualificar esse } \\
\text { processo, tendo em } \\
\text { vista suas possíveis } \\
\text { repercussões na } \\
\text { saúde pública. }\end{array}$ \\
\hline $\begin{array}{l}\text { SILVA; } \\
\text { MACHADO, } \\
2013 .\end{array}$ & $\begin{array}{l}\text { Acolhimento às } \\
\text { percepções dos } \\
\text { usuários do } \\
\text { sistema único de } \\
\text { saúde. }\end{array}$ & $\begin{array}{l}\text { Estudo descritivo- } \\
\text { exploratório com } \\
\text { abordagem } \\
\text { qualitativa. Coleta } \\
\text { de dados mediante } \\
\text { entrevista gravada }\end{array}$ & $\begin{array}{l}\text { O tempo de espera } \\
\text { prolongado e a falta de } \\
\text { profissionais e de } \\
\text { informações } \\
\text { adequadas, não } \\
\text { havendo profissionais } \\
\text { em número suficiente } \\
\text { para a demanda da } \\
\text { população. }\end{array}$ \\
\hline $\begin{array}{l}\text { NOGUEIRA; } \\
\text { NEVES, } 2013\end{array}$ & $\begin{array}{l}\text { Prevenção do } \\
\text { câncer de } \\
\text { próstata: atuação } \\
\text { dos enfermeiros } \\
\text { nas unidades de } \\
\text { atenção primária a } \\
\text { saúde. }\end{array}$ & $\begin{array}{l}\text { Trata-se de uma } \\
\text { pesquisa com } \\
\text { abordagem } \\
\text { qualitativa do tipo } \\
\text { exploratória. }\end{array}$ & $\begin{array}{l}\text { A educação em saúde } \\
\text { em conjunto com } \\
\text { outras medidas } \\
\text { importantes para a } \\
\text { saúde da população } \\
\text { masculina pode ajudar }\end{array}$ \\
\hline
\end{tabular}




\begin{tabular}{|c|c|c|c|}
\hline & & & $\begin{array}{l}\text { a diminuir a incidência } \\
\text { do câncer de próstata. }\end{array}$ \\
\hline $\begin{array}{l}\text { SEPARAVICH; } \\
\text { CANESQUI, } \\
2013 .\end{array}$ & $\begin{array}{l}\text { Saúde do homem } \\
\text { e masculinidades } \\
\text { na Política } \\
\text { Nacional de } \\
\text { Atenção Integral à } \\
\text { Saúde do Homem: } \\
\text { uma revisão } \\
\text { bibliográfica. }\end{array}$ & $\begin{array}{l}\text { Para pesquisar os } \\
\text { textos sobre saúde } \\
\text { do homem e } \\
\text { masculinidades, foi } \\
\text { utilizada a } \\
\text { Biblioteca Virtual } \\
\text { em Saúde (BVS). }\end{array}$ & $\begin{array}{l}\text { As diferentes } \\
\text { masculinidades } \\
\text { encontram-se } \\
\text { imbricadas no } \\
\text { processo } \\
\text { saúde/doença vivido } \\
\text { pelos homens. Elas } \\
\text { devem ser } \\
\text { consideradas na busca } \\
\text { da adesão dos } \\
\text { homens aos serviços } \\
\text { de saúde. }\end{array}$ \\
\hline $\begin{array}{l}\text { EID; } \quad \text { KOHN; } \\
\text { MOTTA, } 2014 .\end{array}$ & $\begin{array}{l}\text { Política de saúde } \\
\text { do homem: para } \\
\text { além do que se vê. }\end{array}$ & $\begin{array}{l}\text { Realizou-se uma } \\
\text { pesquisa de cunho } \\
\text { qualitativo, através } \\
\text { da análise do folder } \\
\text { da Campanha } \\
\text { Nacional de } 2009 \\
\text { da PNAISH. }\end{array}$ & 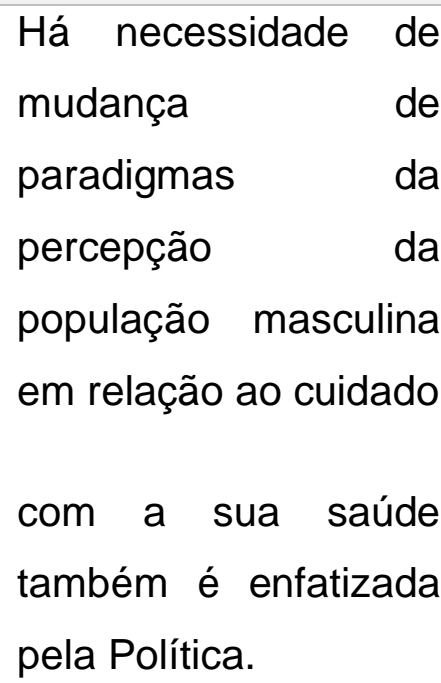 \\
\hline $\begin{array}{l}\text { PINHEIRO; } \\
\text { CABRAL; } \\
\text { BARBOSA, } \\
2015 .\end{array}$ & $\begin{array}{l}\text { Perfil dos homens } \\
\text { participantes do } \\
\text { ensaio } \\
\text { comunitário sobre } \\
\text { prevenção do } \\
\text { câncer de } \\
\text { próstata. }\end{array}$ & $\begin{array}{l}\text { Pesquisa } \\
\text { descritivo-analítica, } \\
\text { transversal e de } \\
\text { caráter } \\
\text { quantitativo, se }\end{array}$ & $\begin{array}{l}\text { Observamos que os } \\
\text { fatores de riscos que } \\
\text { influenciam para o } \\
\text { desenvolvimento do } \\
\text { câncer de próstata } \\
\text { estiveram presentes } \\
\text { no grupo focal. }\end{array}$ \\
\hline
\end{tabular}




\begin{tabular}{|c|c|c|c|}
\hline & & $\begin{array}{l}\text { tratando de um } \\
\text { ensaio } \\
\text { comunitário. }\end{array}$ & \\
\hline $\begin{array}{l}\text { RODRIGUES } \\
\text { et al., } 2016 .\end{array}$ & $\begin{array}{l}\text { Percepção das } \\
\text { equipes de } \\
\text { saúde da } \\
\text { família sobre a } \\
\text { implantação da } \\
\text { política saúde } \\
\text { do homem. }\end{array}$ & $\begin{array}{l}\text { Estudo de abordagem } \\
\text { qualitativa, descritivo } \\
\text { e exploratório, } \\
\text { realizada por meio de } \\
\text { entrevistas } \\
\text { semiestruturadas. }\end{array}$ & $\begin{array}{l}\text { As equipes de } \\
\text { saúde que } \\
\text { trabalham na } \\
\text { atenção primária, } \\
\text { nível selecionado } \\
\text { para implementação } \\
\text { da PNAISH, } \\
\text { precisam ser } \\
\text { envolvidos } \\
\text { capacitados. }\end{array}$ \\
\hline $\begin{array}{l}\text { OLIVEIRA, et } \\
\text { al., } 2016 .\end{array}$ & $\begin{array}{ll}\text { A atuação da } & \text { da } \\
\text { enfermagem } & \\
\text { frente } & \text { às } \\
\text { barreiras } & \\
\text { encontradas } & \text { no } \\
\text { diagnóstico } & \\
\text { precoce } & \text { do } \\
\text { câncer } & \text { de } \\
\text { próstata. } & \end{array}$ & $\begin{array}{l}\text { Pesquisa básica } \\
\text { pautada em uma revisão } \\
\text { da literatura, de } \\
\text { abordagem descritiva, } \\
\text { incluindo avaliação } \\
\text { crítica e sistematizada } \\
\text { de documentos já } \\
\text { publicados. }\end{array}$ & $\begin{array}{l}\text { O cuidado } \\
\text { multidisciplinar é } \\
\text { indispensável, } \\
\text { permite alcançar } \\
\text { resultados positivos e } \\
\text { minimiza o } \\
\text { desconforto do } \\
\text { paciente. }\end{array}$ \\
\hline
\end{tabular}

Fonte: Autoras, 2016.

Enviado: Setembro, 2019.

Aprovado: Outubro, 2019. 